\title{
Method of determining gas storages volumes for settlements gas supply and analysis of energy indicators received in the result of the research
}

\author{
Artashes Petrosyan*, and Artak Petrosyan \\ National University of Achitecture and Construction of Armenia, Teryan Str., 105, 374009 Yerevan, \\ Armenia
}

\begin{abstract}
In order to ensure uninterrupted gas supply to the population, there is a need for its underground storage under high pressures. The value of this pressure depends on the type of soil and its mechanical strength. The volume of storage depends on the number of people living in the area and for what purposes the gas is used. Because it is used for heating, local heat supply and domestic purposes, it is crucial to determine which sources of heat are used by individual and central sources of heat. Therefore, such heat sources have been considered, whose thermal loads have been determined according to the particular region's heat specific expenses and for the provision of local heat supply. Gas consumption was also determined by electric energy indicators of heat sources, heat losses during the transformation and transportation of the heat pipe. Accordingly, it is introduced a method to determine the storage volumes of gas storage facilities of settlements with different quantities of populations, the amount of electric power consumed by compressors and by electric drives for air cooling, the required surfaces.
\end{abstract}

\section{Introduction}

Natural gas fuel combustion products are relatively safe: their sulfur and nitrogen compounds are low in weight and more easily compensated, the combustion temperature is relatively low, and the combustion proceeds without slag generation. As noted in [1], gas transport over thousands of kilometers by a pressure-increase method- from 22 to $40 \mathrm{MPa}$, when it is carried out by gas pipelines of large diameters, such high pressures may be created when it is compressed in multi-stage compressors, having high volumetric capacity and developing high pressure. To increase the energy efficiency of the process, various forms of energy and energy means are consumed, compression is carries out in compressor stations, when gas internal combustion engines (GICE) or electric drives of the

\footnotetext{
${ }^{*}$ Corresponding author: artashespetrosyan@mail.ru
} 
asynchronous or synchronous type are used. In the first case natural gas is used, and in the second case- electricity. The energy efficiency of the transfer process will increase if, prior to gas consumption, when there is a need to reduce (decompression) gas pressure, the irreversible throttle process is replaced by a polyitrop expansion process at the detonatorgenerator type. As a result, about $60 \ldots 70 \%$ of the energy consumed in the compression process will be recovered as a result of the conversion of pressure energy into electricity at the generator site. As a result, the thermodynamic and exergetic efficiency of the gas transport process will increase, but the gas parameters - temperature, specific volume - will decrease. In certain climatic zones, especially in the winter months, artificial warming of expanded gas is needed. Similar studies have also been carried out in [2] when the gas, stored in the gas wells, prior to consumption is subjected to expansion in the facilities of generator type. [2] shows the energy and economic indicators of the observed site. They prove the feasibility of using the abovementioned process and equipment - facility. However, it should be noted that in case of reuse of stored gas, as in gas distribution companies [3], gas losses occur. The results of the study of gas losses and possible ways are presented. They can also be used when reusing gas from gas storages. It is noted that these losses mainly occur at the gas regulation points, in buildings and in cabinets, at 50 and $51 \%$, respectively. However, there are also losses from gas wells in case of storage [4]. According to studies carried out, from underground gas wells, after their prolonged operation, frequently gas losses occur due to emission flows and hidden outflows directed to the inner layers of the soil. As noted in [4], the gas in the well is maintained at the expense of the upper layers consisting of clay or other soil materials, but due to the existence of vertical and horizontal cracks in the geological depth, the gas is subjected to diffusion-convective fluxes impact and tends to the soil surface, then, overcoming the layer's resistance, is emitted into the biolith. This phenomenon is most notable under conditions of high gas pressure when the gas pressure is close to or exceeds the maximum permissible strength of the given soil layers. Similar assumptions are also made in [5].

In the case of gas transportation, it is necessary to regulate the compressor volumetric capacity of the compressor station during the process [6]. This is a consequence of the population's changing gas consumption volumes and the frequency of compressor drives, in this case -frequency of rotation of rotors of gas turbine facilities, needs to be changed. As noted in [6], it is more appropriate to implement them by means of special programs, in accordance with the requirements set out in $[7,8]$. There is also a similar problem with gas storage in gas wells if the gas pipeline is connected to a pipeline that supplies gas to the population. The compressor station need to be changed in volumetric capacity. This can be done in the abovementioned way, or, if synchronous electric drives are used, arranged by adjusting the synchronous electric drive rotation numbers by modifying the voltage in the electric network.

In order to increase gas storage energy efficiency, particular attention should also be paid to gas cooling process in heat exchangers of gas aerial cooling in the compressor separate stages. This has been addressed in $[9,10]$, in particular the problem of gas cooling in heat exchangers of $2 \mathrm{AVG}-75 \mathrm{C}$ type.

In order to increase the energy efficiency of gas storage, it is necessary to ensure the efficient operation of the main and auxiliary equipment included in the compressor station as required by $[11,12,13]$.

From the mentioned literature it follows that in order to ensure a high bandwidth of gas pipelines, it is necessary to commission highway pipeline system of large diameter and with many pipelines and compressor stations. However, even in case of their availability, it is difficult to meet gas demand, particularly in the case of increase in heat demand or peak values in residential areas, in emergency situations of highway pipelines or compressor 
stations. There is a need for special containers in which the in case of minimal gas demand, such as in summer, gas volumes storage is carried out. In particular, underground gas storage facilities have been built and widely used on the pipeline, transporting gas to EU- in Ukraine, in Austria. Similar technologies are also used to ensure uninterrupted gas supply to individual regions in Russia [14a]. Specifically, according to [14b], the Mozyr underground gas storage facility has been operating since 2014 to prepare for the autumnwinter season.

An underground gas storage facility has been built in the 70 s of the last century and currently operates in the village of Ptghni, near Yerevan, Armenia. It aims to provide uninterrupted gas supply to residential and industrial consumers of the republic for about a week. In addition, the Nairit scientific production union, operating with constant production, had its own gashoolders to provide certain volumes of gas. In the former Soviet Union, when there was state ownership, the demands to the issue were understandable, the state had to pay for all, including gas storage costs. Now that those costs are divided by the amount of gas consumed by consumers and the cost of storage is included in the gas tariff, new problem-solving mechanisms are needed. The problem is becoming more difficult by the consumption of gas at different tariffs for different consumers. In particular, the tariff for the population is $139 \mathrm{AMD} / \mathrm{m} 3=\$ 0.29 / \mathrm{m} 3$, and for industrial enterprises with a consumption volume of $10000 \mathrm{~m}^{3}-11621 \mathrm{AMD} / 1000 \mathrm{~m}^{3}$ $=\$ 242.1 / 1000 \mathrm{~m}^{3}$. This means that there is a certain difference between the gas tariffs provided to consumers, and therefore the different cost of storage. 2018 During the period from November to March, approximately maximum 9500 thousand $\mathrm{m}^{3} /$ day and minimum 4000 thousand. $\mathrm{m}^{3}$ / day gas was spent in Armenia. During the summer months these figures are 6800 and 1100 thousand $\mathrm{m}^{3} /$ day respectively. Thus, the tariffs are different and in winter months more gas is consumed by $40 \%$. The latter would mean that for gas storage winter is crucial both in terms of volume and risk, especially for ensuring the livelihoods of the population and a healthy microclimate. Storage of natural gas in one central gas storage facility in Ptghni is not always strategically and technically feasible as there is a risk of blasting and depletion of these wells as well as gas distribution throughout the republic after de-stocking. There is a problem of decentralization of gas wells by regions, settlements, if possible by allocating them separately to large and medium-sized settlements, maintaining appropriate safety and sanitation standards and, in case of groundwater wells- deep wells.

Depending on these factors, the following calculations were made for different numbers: method of determination of the volume of gas wells needed for settlements having $0.15,0.3,1 \mathrm{mln}$ population, due to a certain period of time during the winter season in order to ensure uninterrupted gas supply to the population for 10 days. As a result, the goal is to determine the optimal storage volumes that will be as small as possible by the number of inhabitants, their heat and cold supply loads, type of heat and cold source, technical specifications, and so on. This is the purpose of this article.

\section{Methods}

The gas consumption volumes, according to $[15,16]$, attributed to the volume of gas per capita, are due to the following needs:

a. For the preparation of food and for the supply of hot water, when gas appliances are used: gas stove and water heater, the following monthly volume of natural gas shall be provided: $V_{\text {gaz }}^{\text {heat }}$ pets. plywood, wat.heat $=23.1 \mathrm{~m}^{3} /$ person.month. 
b. For individual heating of separate residential buildings $7 \mathrm{~m}^{3} / \mathrm{m}^{2}$ of living space / month is required. Considering that the living area of one person is in the urban area is 12 $\mathrm{m}^{2} /$ resident, then the gas consumption for heating per month will be: $V_{\text {gaz pers. }}^{\text {hea }}=7 \times 12=84 \mathrm{~m}^{3} /$ month or $420 \mathrm{~m}^{3} /$ season. However, these data relate to the calculated winter outside air temperature in Moscow, which is significantly lower in Armenia, especially for Yerevan, so there is a need to apply other provisions. They are applicable to carry out options comparisons. As such they are:

- The maximum heat consumption for the calculated outdoor air temperature in Yerevan is $855 \mathrm{~W} / 1$ person [17], and the seasonal average heat load per season, when we have heating system energy efficiency criterion of 0.514 , the coefficient of security 0.92 , is: $q_{\text {aver.mon. }}^{1 \text { pers. }}=855 \times 0.514=440 \mathrm{~W} / 1$ person. This specific load can be provided by various heat sources. In Yerevan, the following equipment is used as heat sources in some proximity, in terms of the corresponding $\eta_{\text {therm.COP }}^{i}$ average seasonal heat efficiency and the specific weight in total (expressed as a percentage).

a. gas furnace - $\eta_{\text {term.COP }}^{\text {gazheater }}=0.6, c_{\text {ther }}=15 \%, \quad$ b. gas turbo-furnace$\eta_{\text {term.COP }}^{\text {gaztur.heater }}=0.7, c_{\text {ther }}=20 \%$, c. in - apartment gas boiler of small thermal capacity $\eta_{\text {term } C O P}^{\text {g.heat }}=0.85, c_{\text {ther. }}=30 \%, \mathrm{~d}$. other types of heat sources- wood furnaces, electric heaters, heat pumps, cogeneration plant, etc. $c_{\text {ther. }}=35 \%$.

As a result, the following expression is used to determine the specific gas consumption per person for a building during the heating season:

$$
\begin{aligned}
& v_{\text {gaz.sez. }}^{1 \text { pers. }}=\frac{q_{\text {aver.mont }}^{1 \text { pers. }} \cdot Z_{\text {sez. }} \cdot 3600}{B_{\text {gaz.work }}^{\text {Law.work }}}\left[\frac{\frac{c_{\text {ther. }}}{\sum \eta_{\text {term.coP }}^{\text {i. }}}}{\sum c_{\text {ther. }}}\right]=\frac{440 \cdot 3600 \cdot 3600}{35 \cdot 10^{6}} . \\
& {\left[\frac{\frac{0.15}{0.6}+\frac{0.2}{0.7}+\frac{0.3}{0.87}}{0.15+0.2+0.3}\right]=225,35, \mathrm{~m}^{3} / 1 \text { person } * \text { seaz..., }}
\end{aligned}
$$

Where $B_{\text {gaz }}^{\text {Low.work }}=35 \cdot 10^{6} \mathrm{~kJ} / \mathrm{m}^{3}$ - is the working heat quantity, generated from gas combustion.

- For the purpose of hot water supply, with $24 \mathrm{~h}$ duration, in the case of the abovementioned heat sources, when the specific heat energy consumption is 377 $\mathrm{W} / 1$ person , and the water heating shall be carried out by means of a gas water heater:

$\eta_{\text {term.COP }}^{\text {wat.heat. }}=0.6, c_{\text {ther.. }}=15+20 \%$, and through operating small boiler $\eta_{\text {het.boil.COP. }}^{\text {g.heat }}=0.8, \quad c_{\text {ther.. }}=30 \%$, then the gas seasonal consumption will be 197.49 $\mathrm{m}^{3} / 1$ person.seas.

- For domestic purposes, when the gas is used only for the gas stove, the specific gas consumption per person per season will be $15 \ldots 25 \mathrm{~m} 3 / 1$ person.seas. 
Thus, gas consumption for a given city, township, or residential district with a given population, in the heating season in case of $3624 \mathrm{~h} / \mathrm{sec} .=5$ months / season, will be $\left(\mathrm{m}^{3} / \mathrm{sec}\right)$ :

$$
\begin{aligned}
\sum_{\text {smount }} V_{\text {gazcity }}^{\text {heat.sez }} & =(225.35+197.49+25) \cdot 1000000=447,84 \cdot 10^{6}, \\
\sum_{5 \text { mount }} V_{\text {gazsest. }}^{\text {heat. sez }} & =(225.35+197.49+25) \cdot 300000=134.35 \cdot 10^{6}, \\
\sum_{\text {smount }} V_{\text {gazdist. }}^{\text {heat. }}, & =(225.35+197.49+25) \cdot 150000=67.2 \cdot 10^{6},
\end{aligned}
$$

These numbers represent the volumes that will be required for a city, township, and residential district in terms of $100 \%$ seasonal security coefficient. When it is necessary to meet peak gas demand for 10 days, then the volumes of gas needed for storage shall be (m3 / dem. seas.):

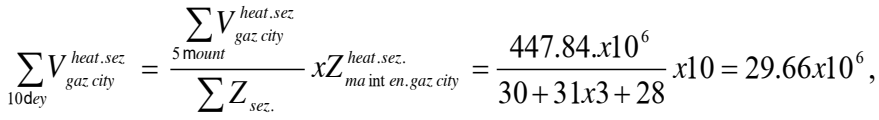

$$
\begin{aligned}
& \sum_{10 \mathrm{~d} a t} V_{\text {gaz seat. }}^{\text {heez }}=8.87 \times 10^{6}, \sum_{10 \mathrm{~d} a t} V_{\text {gaz }}^{\text {heat.sez }}=4.45 \times 10^{6}
\end{aligned}
$$

In fact, underground gas storage facilities need to be designed to store the given volumes of natural gas.

It has been accepted that the geological properties of the soil in the vicinity of these settlements allow to carry out gas storage and the maximum pressure is $6 \mathrm{MPa}$. Two-stage compressors are used to develop it, for which three-phase synchronous electric engines can be used as drives. Such a measure would help to reduce the additional gas consumption for the gas internal combustion drive (GICD), reduce the noise caused by its operation, provide greater reliability, and so on.

Gas storage is planned to be carried out during the summer months when residential consumption is down. Storage duration is 15 days, inlet gas pressure is $1 \mathrm{MPa}$, temperature is $20 \mathrm{oC}$. When re-using stored gas during the heating season, the working pressure of the gas should be reduced to $1.0 \mathrm{MPa}$, by reducing the gas pressure from the wells by throttleing, ensuring $5 \ldots 7 \mathrm{oC}$ gas temperature. If necessary, gas heating can be provided to maintain this temperature.

The daily volumetric consumption of stored gas for settlements shall be determined:

$$
\begin{gathered}
\sum_{15 \mathrm{~d} a y} V_{\text {main.gaz.city }}=\frac{\sum_{10 \mathrm{~d} e y} V_{\text {gaz.city }}^{\text {heat.sez }}}{Z_{\text {main.gaz.city }}}=\frac{29.9 \times 10^{6}}{15}=1.977 \times 10^{6}, \quad(3), \mathrm{m}^{3} / \mathrm{day} \\
\sum_{15 \mathrm{~d} a y} V_{\text {main.gaz.set. }}=0.58 \times 10^{6}, \sum_{15 \mathrm{~d} a y} V_{\text {main.gaz.dist. }}=0.297 \times 10^{6}, \mathrm{~m}^{3} / \mathrm{day}
\end{gathered}
$$

As the storage should be carried out in the natural light conditions, from $7^{00}$ to $19^{00}$, 12 hours, the compressor station capacity will be:

$$
\sum_{12 \mathrm{~h} / \mathrm{day}} V_{\text {comp. }}^{\text {city }}=\frac{\sum_{15 \mathrm{~d} a y} V_{\text {main.gaz.city }}}{Z_{\text {comp.h. }}}=\frac{1.977 \times 10^{6}}{12}=164.75 \times 10^{3}, \quad \text { (4), } \quad \mathrm{m}^{3} / \mathrm{h}=45.8 \mathrm{~m}^{3} / \mathrm{sec}
$$




$$
\sum_{12 \mathrm{~h} / \mathrm{day}} V_{\text {comp. }}^{\text {set. }}=13.43, \sum_{12 \mathrm{~h} / \mathrm{day}} V_{\text {comp. }}^{\text {dist. }}=6.87
$$

In case of determination of gas wells physical volume $-V_{f i z .}^{f a t h}$, it has been accepted that based on the security guarantee condition, it is necessary to fill the $80 \%$ of the well required volume: $\sum V_{\text {lab. }}^{\text {fath. }}=0.8 \cdot V_{\text {fiz. }}^{\text {fath. }}$

The well physical volume shall be filled from the gas pipeline $-V_{o}, \mathrm{~m}^{3}$ and be determined based on the following condition: at the entry the gas pressure is $1 \mathrm{MPa}$, the temperature is $280^{\circ} \mathrm{K}$, and at the exit $-6 \mathrm{MPa}$ and $293,{ }^{\circ} \mathrm{K}$. The wells physical volumes, for the abovementioned settlements, shall be determined by the following expressions:

$$
\sum_{10 \mathrm{~d} e y} V_{\text {gazcity }}^{\text {heat.sez }}=\sum V_{\text {lab. }}^{\text {fath. }} \cdot\left(\frac{p_{\text {lab. }}}{p_{\mathrm{o}}} \cdot \frac{T_{o}}{T_{\text {lab. }}}\right)=0.8 \sum V_{\text {lab. }}^{\text {fath. }}\left(\frac{6}{1.0} \cdot \frac{280}{293}\right)=5.734 \sum V_{\text {lab. }}^{\text {fath. }},
$$

where $p_{\text {lab. }}=6, p_{\mathrm{o}}=1.0$ - are the gas final pressures in the well and gas pipeline, $\mathrm{MPa}$,

$T_{\text {lab. }}=293, T_{o}=280-$ are the gas final temperatures in the well and gas pipeline, ${ }^{0} \mathrm{~K}$,

$$
\begin{gathered}
\sum V_{\text {lab.city }}^{\text {fath. }}=\sum_{10 \mathrm{dey}} V_{\text {gazcity }}^{\text {heet.sez }} / 5.734=29.66 \times 10^{6} / 5.734=5.17 \times 10^{6}, \\
\sum V_{\text {lab.settl. }}^{\text {fath. }}=1.55 \times 10^{6}, \sum V_{\text {labdist. }}^{\text {fath. }}=0.776 \times 10^{6},
\end{gathered}
$$

If the total number of wells is accepted as $\sum n_{\text {fiz. }}^{\text {fath. }}$ respectively 15,5 and 3 , then for any option the well volume will be:

$$
\begin{aligned}
\sum V_{\text {fiz.city }}^{1 \text { fath. }}=\frac{\sum V_{\text {lab.city }}^{\text {fath. }}}{\sum n_{\text {fiz. }}^{\text {fath. }}}=\frac{5.17 \times 10^{6}}{15}=0.34 \times 10^{6} \\
\qquad V_{\text {fiz.sett. }}^{1 \text { fath. }}=0.31 \times 10^{6}, \sum V_{\text {fiz.dist }}^{1 \text { fath. }}=0.259 \times 10^{6}
\end{aligned}
$$

The well lateral dimensions- $h_{\text {fath. }}, D_{\text {fath. }}$ may be determined when one of them is given as $h_{\text {fath. }}=300 \mathrm{~m}$, and for the other we will have:

$$
\begin{aligned}
D_{\mathrm{fath}}^{\text {city }}=\sqrt{\frac{4.0 .41 \times 10^{6}}{3.14 \cdot 300}}=38, \\
D_{\text {fath }}^{\text {sett. }}=36 \mathrm{~m}, D_{\text {fath }}^{\text {dist. }}=33, \mathrm{~m},
\end{aligned}
$$

Compared to the previous one, the Central Heating System (CHS) will be considered, for the operation of which natural gas is used and for its uninterrupted supply underground storage should be organized as in the previous option. The central boiler serves as the heat source for the abovementioned settlements. In this case, from one or more boilers, the high temperature heat pipeline, with the help of central pumps and highway supply and return pipelines, is supplied to the central heat units (CHU). In this case, thanks to the appropriate heat exchangers, a secondary heat pipeline is made at lower temperatures, and through distribution pumps and heat grids is directed to the heat equipment distributed in the 
buildings. Giving its heat and being relatively cooled, the heat pipeline returns to CHU. Similarly, hot water is also provided to consumers for the implementation of the CHS.

The heat losses occurring in the CHS networks and local heat supply heat networks and its other junctions, usually make up 5, 3 and 1\% respectively, or 9\%, respectively. This will mean that the total heat need will increase at the expense of network losses. It will be decided:

$$
\left.\sum Q_{\text {CHSgen. }}^{\text {city }}=1,09 \sum\left(q_{\text {aver.sez. }}^{1 \text { pers. }}+q_{H W S S}^{1 \text { pers. }}\right) N_{\text {pers. }}^{\text {sity }}=1,09 \cdot(440+377) \cdot 1000000\right) \cdot 10^{-6}=890.53 \mathrm{MW}
$$

If regional boiler average seasonal heat efficiency is taken as $0.9 \ldots 0.92$, then the natural gas consumption, in case of the abovementioned heat need, will be:

$$
\sum V_{\text {gaz CHS }}^{\text {city }}=\frac{\sum Q_{\text {CHSgen }}^{\text {sity }}}{B_{\text {gaz. }}^{\text {Lowwork }} \cdot \eta_{\text {goil.aver.sez. }}^{\text {city }}}=\frac{890.53}{35 \times 0.92}=27.66 \mathrm{~m}^{3} / \mathrm{sec}=99562.3 \mathrm{~m}^{3} / \mathrm{h}
$$

For other domestic purposes, when gas stove is used, the natural gas monthly consumption will be $v_{\text {gaz pers. }}=3 \ldots 5 \mathrm{~m}^{3} /$ person, month, and for the city:

$$
\sum V_{\text {gazdom.purp. }}^{\text {city }}=\sum V_{\text {gazCHS }}^{\text {city }} x \sum N_{\text {pers. }}^{\text {sity }}=4 x 1000000=4000000 \mathrm{~m}^{3} / \mathrm{month}=5556 \mathrm{~m}^{3} / \mathrm{h}
$$

Thus, for the city needs, the gas total consumption will be:

$$
\sum V_{\text {gazdom. purp }+ \text { CHS. }}^{\text {city }}=99562.3+5556=105118.3 \mathrm{~m}^{3} / \mathrm{h},
$$

During the heating season, the duration of which in Yerevan is 151 days or $3624 \mathrm{~h} /$ year, the gas consumed volume will be:

$$
\sum_{5} \sum V_{\text {gazdom. purp }+ \text { CHS. }}^{\text {city }}=105118.3 \times 3624=380.9 \times 10^{6} \mathrm{~m}^{3} / \mathrm{seas}
$$

In the result of CHS operation, the gas consumption volumes, compared to the previous option, in the heating season decrease by $\frac{447,84 \cdot 10^{6}}{380.9}=1,176$ or by $17.6 \%$. It is explained by the individual heat sources low energy efficiency.

Similar calculations have also been made for the township, but with the difference that the average seasonal heat efficiency of the regional boiler is 0.9 , due to the decrease in the length of the pipelines, their thermal losses are 3,3 and $1 \%$, and the thermal load and other values resulting therefrom will make up:

$$
\begin{gathered}
\left.\sum Q_{C H S \text { gen. }}^{\text {sett. }}=1,07 \cdot \sum\left(q_{\text {aver.sez. }}^{1 \text { pers. }}+q_{H W S S}^{1 \text { pers. }}\right) N_{\text {pers. }}^{\text {sett. }}=1,07 \cdot(440+377) \cdot 300000\right) \cdot 10^{-6}=262.25 \mathrm{MW}, \\
\sum V_{\text {gaz } C H S}^{\text {sett. }}=\frac{\sum Q_{C H S \text { gen }}^{\text {sett. }}}{B_{\text {gaz }}^{\text {Low.work }} \cdot \eta_{\text {goil.aver.sez. }}^{\text {sett. }}}=\frac{262.25}{35 x 0.9}=8.33 \mathrm{~m}^{3} / \mathrm{sek.}=29972.2 \mathrm{~m}^{3} / \mathrm{h}, \\
\sum V_{\text {gazdom. purp. }}^{\text {sett. }}=\sum V_{\text {gazCHS }}^{\text {sett. }} x \sum N_{\text {pers. }}^{\text {sett. }}=4 x 300000=1200000 \mathrm{~m}^{3} \mathrm{month}=3333,3 \mathrm{~m}^{3} / \mathrm{h} \\
\sum V_{\text {gazdom.purp }+ \text { CHS. }}^{\text {sett. }}=29972.2+3333.3=30305.5 \mathrm{~m}^{3} / \mathrm{h},
\end{gathered}
$$




$$
\sum_{5} \sum V_{\text {gazdom.purp }+ \text { CHS. }}^{\text {sett. }}=30305.5 \times 3624=109,83 \times 10^{6} \mathrm{~m}^{3} / \mathrm{seas}
$$

In this case the mentioned relation will be represented by $\frac{134.35 \cdot 10^{4}}{109.83 \cdot 10^{4}}=1.258$ or is decreased by $25.8 \%$. It is due to the fact that the heat losses in the highway pipelines decrease.

The next option was considered: the residential district, in which the heat source is an intra-regional gas boiler, when the heat pipeline immediately from it, without CHS, with relatively low temperature, as the previous option secondary heat pipeline, is directed to the heating equipment, distributed in the buildings, through the intra-district heat network and intra-district distribution pumps located in the boiler house. Returning its heat again and relatively cooling, the heat pipeline is returned to the boiler house. In the case of such a technological scheme, heat exchangers, central pumps, pipelines, CHS equipment and facilities will be absent. In this case, the heat losses in the distribution grid will make up 4\% (instead of the previous 9 and 7), and the average seasonal heat efficiency of boiler of low capacity will be 0.88 . The calculations will be similar to the previous ones and are as follows:

$$
\begin{aligned}
& \left.\sum Q_{\text {CHS gen. }}^{\text {dist. }}=1,04 \sum\left(q_{\text {aver.sez. }}^{1 \text { pers. }}+q_{H W S S}^{1 \text { pers. }}\right) N_{\text {pers. }}^{\text {sett. }}=1,04 \cdot(440+377) \cdot 150000\right) \cdot 10^{-6}=127.45 \mathrm{MW}, \\
& \sum V_{\text {gaz CHS }}^{\text {dist. }}=\frac{\sum Q_{C H S \text { gen }}^{\text {dist. }}}{B_{\text {gaz }}^{\text {Lowork }} \cdot \eta_{\text {goil.aver.sez. }}^{\text {sdisty }}}=\frac{127.45}{35 \times 0.88}=4.14 \mathrm{~m}^{3} / \mathrm{sec}=14896.75 \mathrm{~m}^{3} / \mathrm{h} \\
& \sum V_{\text {gazdom.purp. }}^{\text {dist }}=\sum V_{\text {gaz CHS }}^{\text {dist. }} x \sum N_{\text {pers. }}^{\text {dist. }}=4 x 150000=600000 \mathrm{~m}^{3} / \mathrm{month}=1666.6 \mathrm{~m}^{3} / \mathrm{h} \\
& \sum V_{\text {gaztom. purp }+ \text { CHS. }}^{\text {dis.. }}=14896.75+1666.7=15063.42 \mathrm{~m}^{3} / \mathrm{h}, \\
& \sum_{5} \sum V_{\text {gaz dom. purp }+ \text { CHS. }}^{\text {dist. }}=15063.42 .5 \times 3624=54.23 \times 10^{6} \mathrm{~m}^{3} / \mathrm{seas} .
\end{aligned}
$$

In this case the mentioned relation will be represented by $\frac{67.2 \cdot 10^{4}}{54.23 \cdot 10^{4}}=1.239$ or is decreased by $23.9 \%$. This is smaller compared to the previous one and is due to the absence of highway pipelines and heat losses in them. However, the average seasonal heat efficiency of the gas boiler is small.

As with individual heat sources, other necessary parameters have been determined. To make them more compact and complete, they are listed in Table 1.

Table 1.Technical indicators of comparable options for different settlements and heat sources

\begin{tabular}{|c|c|c|c|c|c|c|}
\hline Heat supply system & \multicolumn{3}{|c|}{$\begin{array}{c}\text { Individual boiler, furnace, } \\
\text { water heater }\end{array}$} & \multicolumn{3}{|c|}{ Regional gas boiler } \\
\hline Settl. & city & settlement & Res. Dis. & city & settlement & Res. Dis. \\
\hline Tech. spec. & & & &
\end{tabular}


Table 1. Continued

\begin{tabular}{|c|c|c|c|c|c|c|}
\hline $\begin{array}{c}\sum_{10 \mathrm{~d} e y} V_{\text {gazi }}^{\text {heat.sez }} 10^{6} \\
(\mathrm{~m} 3 / \text { dem. seas. })\end{array}$ & 29.66 & 8.87 & 4.45 & 27.66 & 8.38 & 4.14 \\
\hline $\begin{array}{c}\sum_{\substack{10 \mathrm{~d} e y \\
(\mathrm{~m} 3 / \text { dem. seas. })}} V_{\text {gazi }}^{\text {heat.sez }} 10^{6} \\
\end{array}$ & 29.66 & 8.87 & 4.45 & 27.66 & 8.38 & 4.14 \\
\hline $\begin{array}{c}\sum_{15 \mathrm{~d} a y} V_{\text {main.gaz.i }} \\
10^{6} \mathrm{~m}^{3} / \mathrm{day}\end{array}$ & 1.977 & 0.58 & 0.297 & 1.844 & 0.555 & 0.276 \\
\hline$\sum V_{\text {lab.city }}^{\text {fath }}, \mathrm{m}^{3} / \mathrm{s}$ & 45.8 & 13.43 & 6.87 & 42.7 & 12.86 & 6.39 \\
\hline$\sum V_{\text {lab.city }}^{\text {fath. }}, 10^{6}, \mathrm{~m}^{3}$ & 5.17 & 1.55 & 0.776 & 4.82 & 1.45 & 0.782 \\
\hline$\sum_{10^{6}, \mathrm{~m}^{3} / \mathrm{well} / \mathrm{pcs}}^{1 \text { fath. }}$ & $0.34 / 15$ & $0.31 / 5$ & $0.259 / 3$ & $0.32 / 15$ & $0.29 / 5$ & $0.24 / 3$ \\
\hline $\begin{array}{c}D_{\text {fath }}^{i}, \mathrm{~m}, \\
h_{\text {fath. }}=300\end{array}$ & 38 & 36 & 33 & 37 & 35 & 32 \\
\hline
\end{tabular}

The data presented in the table shows that the volume of stored gas, in case of use of the mentioned settlements and given heat sources, is 7.2\%, 5.8\% and 7.5\% higher for individual heat sources than for the central one. This is due to the high expense of heat source heating, although there are heat losses in the external heat networks and in the internal heat networks, and in the buildings there is a need for heating equipment and so on. As a result of the decrease in the volume of stored gas, the capacity of the compressor station will also decrease by $7.3 \%, 4.4 \%$ and $7.5 \%$ respectively.

The Figure 1 represents the basic scheme of underground gas storage and reuse, which shows that gas is supplied to 11 compressor stations by 12 main gas pipeline, it is purified in 2 from mechanical mixtures, subjected to two-stage compressors, then is subject to compressors 3 , then it is subject to intermediate air cooling 4 and is directed to 18 oil breakers via 16, after being purified from oil is directed to gas holes 21 via 20 distribution pipelines.

Since the volumetric capacity of Compressor stations compressors is due to their electric drive power, the electric power consumption will be different for the options considered.

In the comparable options, to determine the actual electric power expenses, it is necessary to construct two-stage, polytropheic and cooling gas thermodynamic processes in the diagram p-i (see Fig. 2 and detailed in [18]). In it the processes of politrop compression $7-8^{\prime}, 9-10^{\prime}$ and cooling $8^{\prime}-9,10^{\prime}-11$ are occurring they are going through mechanical work consumption and isobaric heat removal process, and those specific values are respectively $l_{7-8^{\prime}}=197, l_{9-10^{\prime}}^{I I}=215, q_{8^{\prime}-9}^{I}=154, q_{10^{\prime}-11}^{I I}=245 \mathrm{~kJ} / \mathrm{kg}$. 


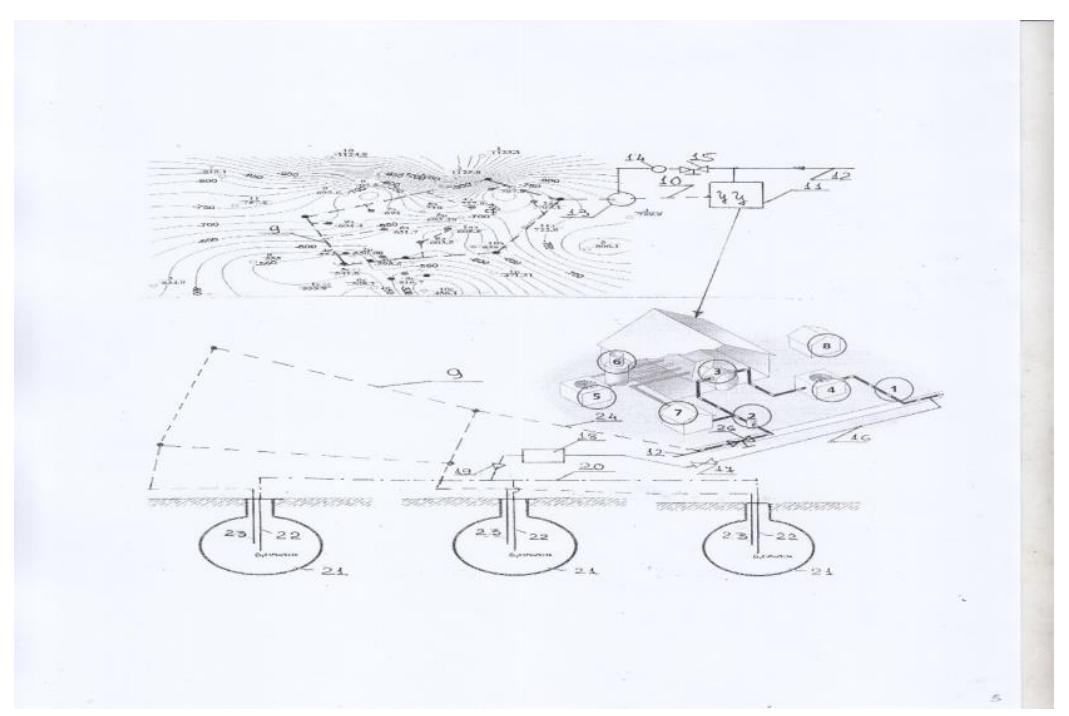

Fig. 1. Natural gas compression and storage technological scheme

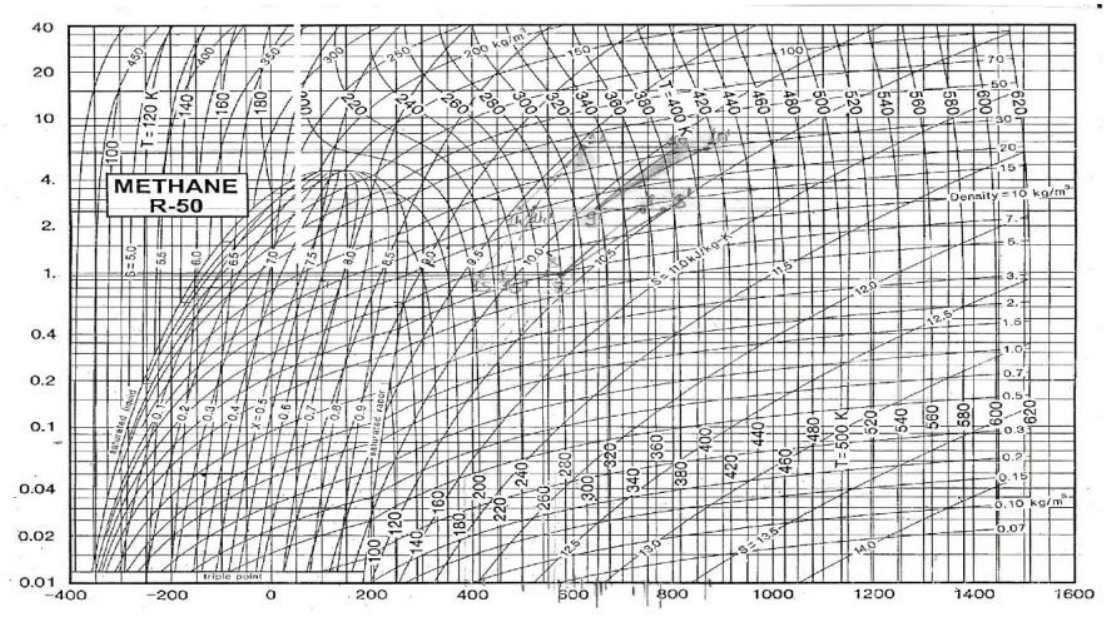

Fig. 2. Description of natural gas two-step, polytrop compression and cooling thermodynamic processes in the diagram

Taking into consideration the values $\sum V_{\text {lab.city }}^{\text {fath }}$ given $\mathrm{n}$ the table 1 , the electric power sum consumptions will be determined in electric drives of compressors I and II degrees, as well as the air cooling heat exchanger surfaces for the comparative options, the required air quantities with the help of air ducts. They will also determine the consumption of electric power consumed by electric drives. The results of this calculation are presented in Table 2 .

The actual volumetric capacity of reciprocal compressor $[18,19,20\}$ is determined by the following expression: $V_{\text {fol.exp. }}=G_{a} v_{7}$, where $G_{a}{ }^{-}$is the working body mass consumption, $\mathrm{kg} / \mathrm{sec}, v_{7}-$ is the natural gas specific volume in the compressor inlet (Fig. 
2). The compressor specific volumetric capacity is determined by $V_{\text {voi.c. }}=V_{\text {foi.exp.. }} / \lambda$ where $\lambda$ - is the compressor propulsion coefficient. It is determined by the following expression: $\lambda=\lambda_{i} \cdot \lambda_{\omega^{\prime}}$ where $\lambda_{i}$ is the compressor indicator propulsion coefficient, $\lambda_{\omega^{\prime}}$ is the coefficient taking into account the loss of irreversibility caused by the difference in temperature between the inlet and outlet gases. $\lambda_{i}$ the indicator impulse coefficient is determined by the following formula:

$$
\lambda_{i}=\frac{p_{o}-\Delta p_{\text {inl.. }}}{p_{o}}-c x\left[\frac{p_{\text {İ }}-\Delta p_{\text {outl. }}}{p_{o}}-\frac{p_{o}-\Delta p_{\text {inl.. }}}{p_{o}}\right]
$$

where $\Delta p_{\text {outl. }}, \Delta p_{\text {inl.. }}$ bar - is the rate of decrease in natural gas pressure in the exhaust and inlet processes in the compressor inlet and outlet valves (bar) as a result of the throttling processes in them: $\Delta p_{\text {outl. }} \Delta p_{\text {inl. }}=0.05-0.1$ bar,$c-$ is the compressor dead volume and is conditioned by the compressor type, pistons arrangement, productivity, form of working body, etc.[21, 22, 23]: $c=0.05 \ldots 0.1$ : For reciprocal compressors of high productivity, $c=0.07: \lambda_{\omega^{\prime}}$ is determined: $\lambda_{\omega^{\prime}}=T_{\text {inl. }} / T_{\text {out }}$ is the ratio of the absolute temperatures of the natural gas at the inlet and outlet of the compressor and they are taken as shown in the Figure 2 .

As currently reciprocal compressors, as well as compressors of pistons horizontal alignment of high productivity are widely used, then according to the abovementioned method, when $p_{o}^{I}=0.1, p_{k}^{I}=2.45, p_{o}^{I I}=2,45, p_{k}^{I I}=6 \mathrm{MPa}, \quad c^{I}=0.05, c^{I I}=0.07, \quad$ the following values have been determined:

$$
\lambda^{I}{ }_{i}=0.885, \lambda^{I} \omega^{\prime}=0.745, \lambda_{I}=0.659, \lambda^{I I}{ }_{i}=0.925, \lambda_{\omega^{\prime}}=0.78, \lambda_{I I}=0.712 .
$$

The table 2 shows that, as a result of the decrease of volumetric consumption of stored gas and therefore the decrease of compressor station output, the compressor capacities for I and II degrees are significantly reduced compared to the option of individual heat sources. As a result, the electric power consumption also decreases during the 15 day period of natural gas storage or during the given season. These relations are respectively:

$$
\sum_{15 \text { day ir. }} N_{1+1 \mathrm{ll}}^{\text {reg.sez. }} / \sum_{\text {15daycent.. }} N_{1+\|}^{\text {reg..sez. }}=7.26,4.43,7,51 \%
$$

As mentioned above, it is necessary to determine the surface area of the heat exchanger required for gas cooling in compressor 1 and II degrees as follows:

$$
F_{\text {heateh. }}^{I, I I}=\frac{Q^{I, I I}{ }_{\text {heat eh } i}}{\mathrm{k}_{\text {heat eh }} x \Delta t^{I, I I} \text { щзз..Йбi. }}=\frac{M_{I, I I} * q_{8^{\prime}-9}^{I}\left(q_{10^{\prime}-11}^{I I}\right)}{\mathrm{k}_{\text {heat eh }} * 30,76(40,67)}, \quad \mathrm{m}^{2},
$$

where $q_{8^{\prime}-9}^{I}=154, q_{10^{\prime}-11}^{I I}=245 \mathrm{~kJ} . \mathrm{kg}$. 


\section{Results}

The results are presented in Table 2, the study of which shows that in the case of an individual heat source in the same settlements conditions, when comparing them with the CHS option, the air cooling heat exchangers surfaces are respectively greater: I degree - by 41.8, 38, 42.1, II degree - 7. 3, 4.4, 7.5\%.

Table 2. The actual volumetric capacities, mass expenses, electrical capacities, and electric power costs at different grades of the two-stage compressor, in conditions of labor pressures

\begin{tabular}{|c|c|c|c|c|c|c|c|c|}
\hline \multirow{2}{*}{$\begin{array}{l}\text { Value } \\
\text { deg. }\end{array}$} & \multirow[t]{2}{*}{$\begin{array}{c}V_{\text {fol.exp. }}^{i}, \\
\mathrm{~m}^{3 / \mathrm{s}}\end{array}$} & \multirow[t]{2}{*}{$\begin{array}{c}V_{\text {voi.c.. }}^{i} \\
\mathrm{~m}^{3} / \mathrm{s}\end{array}$} & \multirow[t]{2}{*}{$\begin{array}{c}M_{i}, \\
\mathrm{~kg} / \mathrm{s}\end{array}$} & \multirow[t]{2}{*}{$\begin{array}{l}N_{\text {comp. }}^{\text {i deg }} \\
\text { MW }\end{array}$} & \multirow[t]{2}{*}{$\begin{array}{l}\sum_{15 \text { day }} N_{\mathrm{l}+\mathrm{Il}}^{\text {reg.sez }} \\
\text { MW.h/seas }\end{array}$} & \multirow[t]{2}{*}{$\begin{array}{c}F_{\text {heateh }}^{I} / F_{\text {heateh }}^{I} \\
\mathrm{~m}^{2}\end{array}$} & \multirow{2}{*}{\begin{tabular}{|c|}
$N_{\text {went.. }}^{\mathrm{I}}$ \\
$\begin{array}{l}N_{\text {went.. }}^{\mathrm{II}} \\
\mathrm{MW}\end{array}$
\end{tabular}} & \multirow{2}{*}{$\begin{array}{c}\sum_{12 * 15} N_{\text {went. }}^{1} \\
\sum_{12 * 15} N_{\text {vent. }}^{\text {II }}, \\
\text { MW.h/seas }\end{array}$} \\
\hline & & & & & & & & \\
\hline \multirow[t]{6}{*}{ I deg. } & 69,5 & 45,8 & 486,0 & 95,7 & & 81107 & 1,4 & 253,75 \\
\hline & 20,4 & 13,4 & 142,5 & 28,1 & & 23783 & 0,41 & 74,4 \\
\hline & 10,4 & 6,9 & 72,9 & 14,4 & & 12166 & 0,21 & 38,1 \\
\hline & 64,7 & 42,7 & 453,1 & 23,9 & & 57196 & 1,31 & 210,5 \\
\hline & 19,5 & 12,9 & 136,5 & 26,9 & & 17226 & 0,4 & 71,2 \\
\hline & 9,7 & 6,4 & 67,8 & 13,4 & & 7616 & 0,2 & 33,8 \\
\hline \multirow[t]{6}{*}{ II deg. } & 25,6 & 35,9 & 271,8 & 58,4 & 27753,9 & 72171 & 1,25 & 35,4 \\
\hline & 7,5 & 10,5 & 79,7 & 17,1 & 8138,3 & 21163 & 0,37 & 66,2 \\
\hline & 3,8 & 5,4 & 40,8 & 8,8 & 4163,1 & 10826 & 0,19 & 33,9 \\
\hline & 23,8 & 33,5 & 253,4 & 54,5 & 25875,4 & 50895 & 1,16 & 210,5 \\
\hline & 19,5 & 12,9 & 136,5 & 16,4 & 7792,9 & 15328 & 0,35 & 63,4 \\
\hline & 7,2 & 10,1 & 76,3 & 8,2 & 3872,2 & 7616 & 0,17 & 31,5 \\
\hline
\end{tabular}

These are the consequence of the change in the thermal loads of these heat exchangers when natural gas of different volume output is subject of compression. In the result, the air quantities used for air cooling and air ducts volume outputs will also be different, as well as the electric power of the air ducts electric engines and the electric power expenses during the gas storage period. These will be determined by the following formulas:

$$
\begin{aligned}
& V_{\text {went.. }}^{\mathrm{i}}=\frac{Q_{i}}{c_{\text {b№ }}^{\text {sam. }} \cdot \rho_{\text {b№ }}^{\text {sam.. }} \cdot \Delta t_{\text {b№ }}^{\text {sam.. }}}=0,0879 Q_{i}, N_{\text {went.. }}^{\mathrm{i}}=\frac{V_{\text {went.. }}^{\mathrm{i}} \cdot \Delta p_{\text {went. }}^{\mathrm{i}}}{\eta_{\text {air }}^{\text {sam. }}}=0,214 \cdot V_{\text {went.. }}^{\mathrm{i}}, \sum_{15 x 12 \mathrm{E}} N_{\text {went. }}^{\mathrm{i}}= \\
& =N_{\text {went. }}^{\mathrm{i}} \cdot 180=38,57 \cdot V_{\text {went. }}^{\mathrm{i}}, c_{\text {air }}^{\text {sam.. }}=1,0063, \rho_{\text {air }}^{\text {sam. }}=1,131, \Delta t_{\text {air }}^{\text {sam.. }}=8, \eta_{\text {air }}^{\text {sam. }}=0,7, \Delta p_{\text {went.. }}^{\mathrm{i}}=150
\end{aligned}
$$

The values of these estimated values are again shown in Table 2.

By comparing the results, it was determined the electric power consumption of the air ducts electric drives, and then the electric power consumption for the needs of the compressors and air ducts in the whole storage process. They are respectively:

a. in case of individual heat sources option- 479.54, 140.62, 71.93 l 28233.44, 8278.93, 4235.02 12 MW.h/r.seas. 
b. In case of CHS option- 447.08, 134.65, 66.91 lu 26322.44, 7927.56, 3939.12 MW.h/r.seas.

The Figures show that, in the case of the CHS option, the electric power consumption required for storage, compared to the individual heat source option, is less in the same quatity as the volume outputs subject to storage - 7.3, 4.4 and $7.5 \%$ : For comparable options, they have been preserved, as the compression processes at different degrees of compressors, gas cooling processes in heat exchangers are at the same pressure and temperature ranges. This would mean that in the case of the CHS option, the energy expenses would be reduced in the result of the heat sources empowerment and the use of advanced technologies in the field.

Referring to the energy indicators of the CHS option, it is noticeable that they depend on the population quantity, due to thermal losses in the heat supply system (HSS), energy efficiency of the heat source. This means that from the energy respect the storage of gas is feasible for settlements with populations of $0,3 \ldots 0,4 \mathrm{mln}$. within the population. The results of similar calculations prove this. It will be considered optimal and appropriate in the context of such problems. However, we will get the final answer from the calculation and comparison of the energy indicators, which is beyond the scope of the material.

\section{Conclusions}

- In the heating season, to ensure the uninterrupted supply of gas, it is appropriate to carry out gas storage individually for individual settlements in order to facilitate the preparation of storage facilities and the payment of operating costs associated with them.

- When determining the volumes of gas storage, it is necessary to take into account the number of inhabitants in the settlements, the type of their heat sources and the energy efficiency,

- CHUs can be an appropriate system, because compared to the option of individual heat source, energy costs are reduced due to heat sources empowerment and application of advanced technologies in the field,

- from energy respect, the storage of gas is advisable for settlements with a population of $0,3 \ldots 0,4 \mathrm{mln}$. living within.

\section{References}

1. A.V. Klimenko, V.S. Agababov, P.N. Borisova, S.N. Petin, A.V. Koryagin, Thermophysics and Aeromechanics, 25, 613 (2018)

2. A.L. Petrosyan, A.H. Manukyan, NUACA, Bulletin, 4 (4/48), 50 (2017)

3. V.Yu. Demchuk, MS Doronin Gas distribution systems: opportunities for increasing energy efficiency. SIC Giproniigas OJSC (2019)

4. E.B. Bukhghalter, B.O. Budnikov, N.V. Mozharova, S.A. Kulachkova

5. N.V. Mozharova, S.A. Kulachkova, Soils and Sediments, 8(6), 434 (2008)

6. B.V. Vovk, P.P. Arefev, Oil and Gas Terminal, 16, 75 (2019)

7. D.N. Glumov, A.V. Strekalov, Tyumen State Oil and Gas University Tyumen, Russia, 194

8. O. S. Radchenko, S. Yu. Podorozhnikov, E.V. Ogudova, Oil and gas terminal, Sat. Art. Int. scientific and technical conf. Tyumen: Vector Buk, 13, 187 (2017) 
9. V.B. Kuntysh, N. M. Kuznetsov, Energoatomizdat, 280 (1992)

10. A. N. Bessonny, V. B. Kuntysh, Fundamentals of calculation and design of air-cooled heat exchangers: reference book, 512 (1996)

11. A.F. Komova, Oil and Gas Terminal, 16, 151 (2019)

12. A.G.Vertesov, A.S. Losatin, Gas industry, 3(674), 59 (2012)

13. A.F. Kalininko, V.V. Kepchatov, A.Y. Toporov, Transactions of Russian State University of Oil and Gas after I. Gubkin, 4, 85 (2009)

14. Materials of the GAZPROM scientific conference - ARMENIA, Yerevan, (2014); a. Speaker: V. Reznik, Kaliningrad Department of Underground Gas Storage: Results of gas injection into the Kaliningrad UGSF in 2014, gas balance, preparations for the selection and modes of gas withdrawal from UGSF in the autumn-winter period 2014/2015; b. Speaker: Yu.P. Ananich, Results of gas injection into the Mozyr UGSF in 2014, gas balance, preparations for the selection for gas and modes of gas withdrawal from the UGSF in the autumn-winter period 2014/2015

15. Gas distribution systems (2012)

16. Methods of conducting heat engineering calculations. met. instructions, 234 (2009)

17. A.L.Petrosyan, A.G. Avetisyan, Union of builders of Armenia, 8-9, 181 (2012)

18. A.L.Petrosyan, A.KH. Grigoryan, NUACA, 4(4/48), 50 (2015)

19. A.L. Petrosyan, NUACA, I(58), 30 (2018)

20. A.L.Petrosyan, NUACA, Union of Builders of Armenia, III(70), 75 (2018)

21. Web - site Ural Compressor Plant OJSC (2016)

22. "Penzkompressormash" OJSC, compressor installations and stations at small and medium bases, www.pkm.ru (2019)

23. "OJSC Sumy Machine-Building Plant”, Compressor plants and stations, www.smz.ru (2018) 